\title{
Allergen and endotoxin exposure in a companion animal hospital
}

Sadegh Samadi, Dick J J Heederik, Esmeralda J M Krop, et al.

Occup Environ Med 2010 67: 486-492 originally published online June 2, 2010

doi: $10.1136 /$ oem.2009.051342

Updated information and services can be found at:

http://oem.bmj.com/content/67/7/486.full.html

These include:

References This article cites 37 articles, 6 of which can be accessed free at: http://oem.bmj.com/content/67/7/486.full.html\#ref-list-1

Email alerting Receive free email alerts when new articles cite this article. Sign up in the service box at the top right corner of the online article.

\section{Notes}

To request permissions go to:

http://group.bmj.com/group/rights-licensing/permissions

To order reprints go to:

http://journals.bmj.com/cgi/reprintform

To subscribe to BMJ go to:

http://journals.bmj.com/cgi/ep 


\title{
Allergen and endotoxin exposure in a companion animal hospital
}

\author{
Sadegh Samadi, ${ }^{1,2}$ Dick J J Heederik, ${ }^{1}$ Esmeralda J M Krop, ${ }^{1}$ Ali-Reza Jamshidifard, ${ }^{2}$ \\ Ton Willemse, ${ }^{3}$ Inge M Wouters ${ }^{1}$
}

1 Division of Environmental Epidemiology, Institute for Risk Assessment Sciences (IRAS), Utrecht University, Utrecht, the Netherlands

${ }^{2}$ Occupational Health Department, Arak University of Medical Sciences, Arak, Islamic Republic of Iran

${ }^{3}$ Department of Clinical

Sciences of Companion Animals, Faculty of Veterinary Medicine, Utrecht University, Utrecht, the Netherlands

\section{Correspondence to}

Sadegh Samadi, Division of Environmental Epidemiology, Institute for Risk Assessment Sciences (IRAS), Utrecht University, PO Box 80178, 3508 TD Utrecht, the Netherlands; S.Samadi@uu.nl

Accepted 2 December 2009

\section{ABSTRACT}

Background Exposure to allergens, both in general and occupational environments, is known to result in sensitisation and exacerbation of allergic diseases, while endotoxin exposure might protect against allergic diseases. This may be important for veterinarians and co-workers. However, exposure levels are mostly unknown. Objective We investigated the allergen and endotoxin exposure levels of veterinary medicine students and workers in a companion animal hospital.

Methods Airborne and surface dust was collected using various sampling methods at different locations. Allergen levels in extracts were measured with sandwich ELISAs and/or the multiplex array for indoor allergens (MARIA). Endotoxin was determined by limulus amebocyte lysate (LAL) assay.

Results Fel d 1 (Felis domesticus), Can $\mathrm{f} 1$ (Canus familiaris) and endotoxin were detected in all except stationary samples. The geometric mean (GM) level of personal inhalable dust samples for Fel d 1 was $0.3 \mathrm{ng} /$ $\mathrm{m}^{3}$ (range: below lower limit of detection $(<\mathrm{LOD})$ to 9.4), for Can f $13.6 \mathrm{ng} / \mathrm{m}^{3}(<\mathrm{LOD}$ to 73.3$)$ and for endotoxin $4.4 \mathrm{EU} / \mathrm{m}^{3}(<\mathrm{LOD}$ to 75$)$. Exposure levels differed significantly between job titles, with highest allergen exposure for student assistants in the intensive care unit (Fel d 1, GM $1.5 \mathrm{ng} / \mathrm{m}^{3}$; Can f 1, GM $18.5 \mathrm{ng} /$ $\mathrm{m}^{3}$ ), and highest endotoxin exposure for students (GM $\left.10.1 \mathrm{EU} / \mathrm{m}^{3}\right)$. Exposure levels in dust captured by diverse sampling methods correlated with each other $(p<0.05)$.

Conclusion Allergen exposure likely occurs during veterinary practice, with relatively low endotoxin levels. Future research should investigate dose-response relationship between airborne allergen exposure and health effects.

\section{INTRODUCTION}

Exposure to animal allergens has been implicated as a major risk factor for sensitisation and allergic diseases such as asthma and allergic rhinitis. ${ }^{1} 2$ Animal allergen sensitisation and asthma are also well-known occupational health risks. ${ }^{3}$ This is best described for laboratory animal workers exposed to rat and mouse, ${ }^{4}{ }^{5}$ but might also be important for veterinarians. $^{3}$ The main animals treated in companion animal hospitals are cats and dogs, which are well known allergen producers. The major allergen for cat is Fel d 1 (Felis domesticus) and for dog, Can $\mathrm{f} 1$ (Canus familiaris). ${ }^{4}$ Contact with cats and/or dogs has been reported as a cause of self-reported work-related respiratory symptoms in veterinarians ${ }^{3}$ and laboratory animal workers, ${ }^{6}$ but there have been few studies on allergen exposure levels.

\section{What this paper adds}

- Allergen exposure is likely for veterinary medicine students and workers in a companion animal hospital, while endotoxin exposure is low.

- Settling dust samples collected through electrostatic dust-fall collectors can be used to detect airborne allergen levels even though airborne dust levels are low.

- The surfaces of floors and tables were shown to be potent secondary sources for bio-aerosol exposure.

- Since allergen exposure is likely to occur during veterinary practice, control measures as primary prevention, or a health surveillance program, should be implemented in such occupational settings.

During the last decades, a possible protective effect of endotoxin exposure on the development of allergies and asthma has been suggested. ${ }^{7}$ Endotoxins are integral cell wall component of various Gram-negative bacteria. ${ }^{9}$ Exposure to endotoxins is well-known for workers in agricultural industries ${ }^{10}$ and has been reported for laboratory animal workers as well. ${ }^{11}$ As little is known concerning exposure among veterinarians and their assistants, ${ }^{12}$ we therefore determined allergen and endotoxin exposure levels for veterinarians, animal technicians and students working in a companion animal hospital.

Various sampling methods to collect dust for measuring allergens ${ }^{13}$ and/or endotoxin ${ }^{14}$ have been described. In occupational settings, active airborne inhalable dust sampling is the most frequently applied method. ${ }^{15}$ Studies that measured airborne allergen levels of Fel d 1 and Can f 1 in homes or public spaces reported very low or non-detectable levels. ${ }^{13} 14$ We therefore collected dust using several other methods besides personal dust sampling, such as the collection of reservoir dust by vacuuming the floor ${ }^{16}$ and the collection of table surface dust through wipe sampling. ${ }^{17}$ Furthermore, we explored the feasibility and efficiency of electrostatic dust-fall collectors (EDCs) which collect ambient settling dust for allergen exposure assessment. ${ }^{18}$

Thus, the objective of this study was to characterise exposure levels to allergens and endotoxin in a companion animal hospital using various dust collection methods. 


\section{METHODS \\ Study design}

This study was performed in a companion animal hospital at the Faculty of Veterinary Medicine of Utrecht University, the Netherlands. Dust was collected using five different sampling methods:

- Active personal inhalable dust collection

- Stationary inhalable dust collection

- EDC settling dust collection

- Floor dust collection

- Table surface dust collection.

Samples were collected at various worksites within the hospital: operation room, recovery room, intensive care unit, inpatient ward, examination room, practical teaching room, waiting room, ultrasound room, office and canteen.

Personal inhalable dust sampling was conducted among employees, student assistants and students. Student assistants were veterinary medicine students working during their final year rotation in the companion animal hospital. Students were in their first or second year of veterinary training following a practical course in animal handling and physical examination.

\section{Sampling and analytical procedures}

\section{Active personal and stationary airborne dust sampling}

Personal inhalable dust samples were collected using Gil-Air 5 pumps (Gillian, Clearwater, Florida, USA). Samples were taken in the breathing zone with a PAS-6 sampler equipped with a $25 \mathrm{~mm}$ glass fibre filter (Whatman International, Maidstone, UK) at a flow rate of $21 / \mathrm{min}$. Stationary inhalable dust sampling was performed with the same equipment, positioning the PAS-6 sampler on a tripod at a height of $1.5 \mathrm{~m}$. The glass fibre filters were pre- and post-weighed in a preconditioned room with average temperature $22^{\circ} \mathrm{C}$ (range $21^{\circ} \mathrm{C}$ to $23^{\circ} \mathrm{C}$ ), relative humidity $38 \%$ (35\% to 41\%) and air pressure $1026 \mathrm{mbar}$ (1009-1032). One field blank sample was taken on each sampling day. The dust weight of most samples based on filter blanks was below the lower limit of detection (LOD) of $0.26 \mathrm{mg}$. Filters were stored at $-20^{\circ} \mathrm{C}$ until extraction.

\section{Electrostatic dust-fall collectors}

Plastic EDCs equipped with electrostatic cloths (Zeeman, Alphen aan de Rijn, the Netherlands) were used as described previously. ${ }^{18}$ Briefly, EDCs were opened and placed on top of cupboards or on manufactured wall holders at approximately $170 \mathrm{~cm}$ above floor level, to allow settling dust to be captured by the electrostatic cloths. The sampling area of each cloth was $0.0209 \mathrm{~m}^{2}$. Cloths were made pyrogen-free by heating at $200^{\circ} \mathrm{C}$ overnight prior to sampling. Sampling was conducted for three different time periods in parallel by placing three EDCs alongside each other at each location. The following time periods were considered: 10 work days (EDCs were opened at 07:00 h and closed at 16:00 h every day over a 2-week period, Monday to Friday), 10 days (2 weeks, from Monday 07:00 h to Saturday 07:00 h at a stretch, including night time) and 14 days at a stretch (two continuous weeks). Four field blank samples were taken in each sampling period. After sampling, cloths were transferred to $50 \mathrm{ml}$ tubes (Greiner) and stored at $-20^{\circ} \mathrm{C}$ until extraction.

\section{Floor dust sampling}

Floor dust samples were collected using a $1200 \mathrm{~W}$ vacuum cleaner (Miele, Gütersloh, Germany) equipped with a $25-\mu \mathrm{m}$ mesh nylon sock (Allied Filter Fabrics, Sydney, Australia) as previously described. ${ }^{19}$ An area of $2 \mathrm{~m}^{2}$ of smooth flooring was vacuumed for $2 \mathrm{~min}$. Samples were collected at the end of the work shift, before cleaning. Socks were pre- and post-weighed in a preconditioned room with average temperature $23^{\circ} \mathrm{C}$ (range $22^{\circ} \mathrm{C}$ to $23^{\circ} \mathrm{C}$ ), relative humidity $37 \%$ (range $36 \%$ to $40 \%$ ) and air pressure 1022 mbar (range 1013-1031). Dust captured in the sock was transferred to $50 \mathrm{ml}$ tubes prior to extraction. Pre- and post-weighing of the tubes revealed a $12 \%$ loss of dust weight while the dust was being transferred from the sock to the tube. Samples were stored at $-20^{\circ} \mathrm{C}$ until extraction.

\section{Table surface dust sampling}

Table surface dust sampling ${ }^{17}$ was carried out using filter papers (55 mm diameter; Schleicher \& Schuell, Dassel, Germany) prewetted with $300 \mu \mathrm{l}$ phosphate-buffered saline containing $0.05 \%$ (v/v) Tween-20 (Merck, Schuchardt OHG, Germany). A surface area of $\sim 0.08 \mathrm{~m}^{2}(30 \times 26 \mathrm{~cm})$ was wiped, with the operator wearing clean gloves. Sampling was carried out on the surfaces of animal exam tables in the examination room $(n=2)$, practical teaching room $(n=1)$, ultrasound room $(n=1)$, intensive care unit $(n=1)$ and inpatient ward $(n=1)$; computer tables in the office $(n=6)$, recovery room $(n=1)$, ultrasound room $(n=1)$, waiting room $(n=1)$, practical teaching room $(n=1)$ and examination room $(n=2)$; equipment tables in the examination room $(n=2)$, operation room $(n=2)$, recovery room $(n=1)$, intensive care unit $(n=1)$ and inpatient ward $(n=1)$; and lunch tables in the canteen $(n=2)$. Samples were collected at the end of the work shift. One field blank sample was taken on each sampling day. Filter papers were stored in $15 \mathrm{ml}$ tubes at $-20^{\circ} \mathrm{C}$ until extraction.

\section{Extraction}

Extraction for endotoxin and allergens was performed as described elsewhere. ${ }^{20}$ Briefly, dust samples were extracted in pyrogen-free water containing $0.05 \%$ (v/v) Tween-20. Personal inhalable and table surface dust samples were eluted in $5 \mathrm{ml}$, EDC dust samples in $20 \mathrm{ml}$ and floor dust samples in $5-20 \mathrm{ml}$, depending on the weight of dust $(<0.5 \mathrm{~g}: 5 \mathrm{ml} ; 0.5-1.0 \mathrm{~g}$ : $10 \mathrm{ml} ; 1.0-2.0 \mathrm{~g}: 20 \mathrm{ml}$ ). After shaking in an end-over-end roller for $1 \mathrm{~h}$, the tubes were centrifuged for $15 \mathrm{~min}$ at $1000 \mathrm{~g}$, and $10 \%$ of the supernatant was harvested and stored at $-20^{\circ} \mathrm{C}$ for endotoxin analysis. The removed volume of supernatant was replenished with the same volume of $10 \times$ concentrated phosphate-buffered saline for allergen extraction. Samples were again shaken for $1 \mathrm{~h}$ in an end-over-end roller, followed by centrifugation for $15 \mathrm{~min}$ at $2000 \mathrm{~g}$. Ten per cent of supernatants were harvested and stored at $-20^{\circ} \mathrm{C}$ prior to allergen analysis.

\section{Allergen and endotoxin detection}

Allergen levels of Fel d 1 and Can $\mathrm{f} 1$ in floor dust samples were assessed with sandwich ELISAs (Indoor Biotechnologies, Charlottesville, Virginia, USA). ${ }^{21}$ Samples with a Fel d 1 concentration below the LOD were also analysed using an amplified ELISA, which used streptavidin/HRP (M2051, diluted 1:20 000; Sanquin, Amsterdam, the Netherlands) instead of avidin/HRP. Floor dust samples were tested in 1:5 to 1:1600 dilutions.

All personal, stationary, EDC and table surface dust samples were tested undiluted using multiplex array for indoor allergens (MARIA) (Indoor Biotechnologies) as described by Earle et al ${ }^{22}$ to determine Fel d 1 and Can f 1, and also Mus m 1, Rat n 1, Der p 1, Der f 1, mite group 2 and Bla g 2.

Endotoxin was determined using a limulus amebocyte lysate (LAL) assay. ${ }^{23}$ A 12-point standard curve was produced over the concentration range $0.049-100 \mathrm{EU} / \mathrm{ml}$ for floor dust samples and $0.012-25 \mathrm{EU} / \mathrm{ml}$ for other samples. Personal inhalable dust samples were tested in 1:20 dilutions, EDC and table dust samples in 1:50 dilutions, and floor dust samples in 1:500 dilutions. 
Table 1 Allergen and endotoxin exposure levels in personal inhalable dust samples

\begin{tabular}{|c|c|c|c|c|c|c|c|c|c|c|c|c|c|}
\hline \multirow[b]{2}{*}{ Job } & \multirow[b]{2}{*}{$\mathbf{N}$} & \multicolumn{4}{|c|}{ Fel d $1\left(\mathrm{ng} / \mathrm{m}^{3}\right)$} & \multicolumn{4}{|c|}{ Can $\mathrm{f} 1\left(\mathrm{ng} / \mathrm{m}^{3}\right)$} & \multicolumn{4}{|c|}{ Endotoxin $\left(\mathrm{EU} / \mathrm{m}^{3}\right)$} \\
\hline & & ND & GM & GSD & Range & ND & GM & GSD & Range & ND & GM & GSD & Range \\
\hline \multicolumn{14}{|l|}{ Students } \\
\hline \multicolumn{14}{|l|}{ Student assistants } \\
\hline Inpatient ward & 8 & 6 & 0.1 & 3.0 & $<\mathrm{LOD}-1.4$ & 2 & 1.5 & 4.1 & $<\mathrm{LOD}-6.8$ & 3 & 3.6 & 4.9 & $<\mathrm{LOD}-71$ \\
\hline Intensive care unit & 3 & 1 & 1.5 & 14.9 & $<\mathrm{LOD}-9.4$ & - & 18.8 & 2.5 & $7.1-43.4$ & - & 5.6 & 1.4 & $3.7-7.5$ \\
\hline Anaesthesiology & 5 & 4 & 0.1 & 2.5 & $<\mathrm{LOD}-0.6$ & 2 & 1.2 & 4.0 & $<\mathrm{LOD}-6.8$ & 2 & 2.8 & 2.2 & $<\mathrm{LOD}-8$ \\
\hline Animal examination room & 17 & 10 & 0.3 & 4.0 & $<\mathrm{LOD}-6.1$ & - & 3.3 & 2.0 & $1.1-8.7$ & 7 & 3.3 & 2.2 & $<\mathrm{LOD}-20$ \\
\hline Total & 38 & 23 & 0.2 & 4.6 & $<\mathrm{LOD}-9.4$ & 8 & 2.3 & 3.6 & $<\mathrm{LOD}-43.4$ & 14 & 3.2 & 2.5 & $<\mathrm{LOD}-71$ \\
\hline \multicolumn{14}{|c|}{ Animal technicians (employees) } \\
\hline Inpatient ward & 4 & 1 & 0.5 & 3.8 & $<\mathrm{LOD}-1.8$ & - & 2.6 & 3.7 & $0.6-14.4$ & - & 5.2 & 3.3 & $1.6-24$ \\
\hline Intensive care unit & 6 & 4 & 0.2 & 5.1 & $<\mathrm{LOD}-2.3$ & - & 7.8 & 2.5 & $3.9-45.9$ & - & 4.5 & 2.3 & $2.0-16$ \\
\hline
\end{tabular}

$<\mathrm{LOD}$, below the lower limit of detection; GM, geometric mean; GSD, geometric SD; N, number of measurements; ND, number of non-detectable samples.

Allergen exposure levels were expressed as $\mathrm{ng} / \mathrm{m}^{3}$ for personal inhalable dust samples, $\mathrm{ng} / \mathrm{m}^{2}$ and $\mathrm{ng} / \mathrm{mg}$ of dust for floor dust samples, and $\mathrm{ng} / \mathrm{m}^{2}$ for the EDC and table surface dust samples. Endotoxin exposure levels were expressed in $\mathrm{EU} / \mathrm{m}^{3}$ for personal inhalable dust samples, $\mathrm{EU} / \mathrm{m}^{2}$ and $\mathrm{EU} / \mathrm{mg}$ of dust for floor dust samples, and $\mathrm{EU} / \mathrm{m}^{2}$ for the EDC and table surface dust samples.

Samples with allergen or endotoxin levels below the LOD were replaced with a value of two-thirds of the LOD. The average LOD of the Fel $\mathrm{d} 1$ and Can $\mathrm{f} 1$ of ELISA used for floor dust samples was 3 and $1.5 \mathrm{ng} / \mathrm{m}^{2}$, respectively. For the amplified Fel d 1 ELISA, it was $0.04 \mathrm{ng} / \mathrm{m}^{2}$. The average LOD of MARIA assay for Fel d 1, Can f 1, Mus m 1, Rat n 1, Der p 1, Der $\mathrm{f} 1$, mite group 2 and Bla g 2 corresponds to a LOD of $0.03,0.10$, $0.01,0.06,0.1,0.1,0.6$ and $6.8 \mathrm{ng} / \mathrm{m}^{3}$ for personal dust samples; $0.25,0.75,0.1,0.5,0.8,0.8,0.5$ and $52 \mathrm{ng} / \mathrm{m}^{2}$ for table surface dust samples; and 0.87, 2.61, 0.3, 1.6, 2.6, 2.6, 1.6 and $182 \mathrm{ng} / \mathrm{m}^{2}$ for EDC dust samples, respectively. The average LOD of endotoxin for personal dust samples was $4.8 \mathrm{EU} / \mathrm{m}^{3}$, for table surface dust samples $38 \mathrm{EU} / \mathrm{m}^{2}$, for EDC dust samples $830 \mathrm{EU} / \mathrm{m}^{2}$, and for floor samples $45 \mathrm{EU} / \mathrm{m}^{2}$.

\section{Statistical analysis}

All data were log-normally distributed $(p<0.05)$; therefore, analyses were performed on log-transformed data. Exposure levels were calculated as geometric means (GMs) and geometric standard deviations (GSDs). Differences in exposure concentrations between various locations and jobs were tested using ANOVA, followed by the Tukey-Kramer test as a post hoc test. Pearson correlations were used to assess relationships between parameters. For each location where settling dust samples were collected by EDC, the average allergen concentrations of personal or floor dust samples collected at that location during the EDC sampling period were allocated to the EDC allergen level of the same sampling period in order to compare the different dust sampling methods. Similarly, average concentrations of personal samples collected on the day and at the location of floor dust collection were compared to each other. For this only the 14-day continuous measurements of the EDC samples were used.

Statistical analyses were carried out using SAS v 9.1. Values of $\mathrm{p}<0.05$ were considered to be significant.

\section{RESULTS}

In total, 293 dust samples for allergens and endotoxin were tested. The average sampling time for personal inhalable dust collection was $4.6 \mathrm{~h}$ (range $2-8.5 \mathrm{~h}$ ). The allergen and endotoxin levels of all stationary inhalable samples were below the LOD. Allergen levels of Mus m 1, Rat n 1, Der p 1, Der f 1, mite group 2 and Bla $g$ were below the LOD for all samples.

\section{Personal inhalable dust sampling}

Allergen and endotoxin exposure levels of personal inhalable samples are presented in table 1 . Fel d 1 was not detectable in the majority of personal inhalable dust samples, while Can $\mathrm{f} 1$ was detected. Significant differences in exposure levels between job titles were found for Fel $d 1$ and Can $\mathrm{f} 1(\mathrm{p}<0.05)$, with the highest exposure for student assistants in the intensive care unit (Fel d 1, GM $1.5 \mathrm{ng} / \mathrm{m}^{3}$; Can f 1, GM $18.8 \mathrm{ng} / \mathrm{m}^{3}$ ). Cat allergen exposure levels were significantly higher for students during the practical animal course compared to student assistants in the inpatient ward $(p<0.05)$, while other post hoc comparisons based on job titles were found to be non-significant $(p>0.05)$. Endotoxins were detectable in the majority of personal inhalable dust samples, but at fairly low levels. The highest GM level was observed for students during the practical animal course (GM 10.1 EU/m $\mathrm{m}^{3}$ ).

\section{EDC dust sampling}

Allergen and endotoxin levels in ambient airborne settling dust collected by the EDC are presented in table 2 . Fel $\mathrm{d} 1$ was found in $66 \%$ of the samples, and ranged from below the LOD to $579 \mathrm{ng} / \mathrm{m}^{2}$, whereas Can $\mathrm{f} 1$ was detected in $90 \%$ of the samples, and ranged from below the LOD to $12105 \mathrm{ng} / \mathrm{m}^{2}$. The highest exposure levels of Fel d 1 (GM $349 \mathrm{ng} / \mathrm{m}^{2}$ ) and Can f 1 (GM $10818 \mathrm{ng} / \mathrm{m}^{2}$ ) were observed in the intensive care unit. The allergen levels of Fel $\mathrm{d} 1$ and Can $\mathrm{f} 1$ varied greatly between locations $(p<0.05)$. Endotoxin levels in the EDC samples ranged from below the LOD to $24211 \mathrm{EU} / \mathrm{m}^{2}$ (GM 2276), with the highest exposure levels in the waiting room (GM $\left.10405 \mathrm{EU} / \mathrm{m}^{2}\right)$.

\section{Table surface dust sampling}

Results of allergen and endotoxin exposure levels based on table surface types are presented in table 3 . The GM level of Can $\mathrm{f} 1$ 
Table 2 Allergen and endotoxin exposure levels in EDC settling dust samples (14 continuous days) at different locations

\begin{tabular}{|c|c|c|c|c|c|c|c|c|c|c|c|c|c|c|}
\hline \multirow[b]{2}{*}{ Location } & \multirow[b]{2}{*}{$\mathbf{N}$} & \multicolumn{4}{|c|}{ Fel d $1\left(\mathrm{ng} / \mathrm{m}^{2}\right)$} & \multicolumn{4}{|c|}{ Can f $1\left(\mathrm{ng} / \mathrm{m}^{2}\right)$} & \multicolumn{5}{|c|}{ Endotoxin $\left(\mathrm{EU} / \mathrm{m}^{2}\right)$} \\
\hline & & ND & GM & GSD & Range & ND & GM & GSD & Range & $\mathbf{N}$ & ND & GM & GSD & Range \\
\hline Operation room & 4 & 4 & 9 & - & $<\mathrm{LOD}$ & 1 & 91 & 2.1 & $<$ LOD-202 & 4 & 2 & 518 & 1.6 & $<$ LOD -794 \\
\hline Recovery room & 2 & - & 92 & 1.1 & $88-97$ & - & 1559 & 1.9 & $982-2474$ & 2 & - & 2618 & 4.8 & $870-7922$ \\
\hline Intensive care unit & 2 & - & 349 & 2.0 & $211-579$ & - & 10818 & 1.2 & $9675-12105$ & 2 & - & 9228 & 3.0 & $4182-20366$ \\
\hline Inpatient ward & 3 & 2 & 33 & 10.1 & $<\mathrm{LOD}-482$ & - & 904 & 8.2 & $79-3088$ & 3 & - & 5378 & 4.1 & $1453-24211$ \\
\hline Examination room & 4 & - & 158 & 1.3 & $123-246$ & - & 1356 & 1.6 & $737-2421$ & 4 & - & 2752 & 2.0 & $2437-7288$ \\
\hline Practical teaching room & 2 & - & 240 & 1.1 & $228-254$ & - & 2018 & 1.3 & $1719-2377$ & 2 & - & 9136 & 1.9 & $5773-14536$ \\
\hline Ultrasound room & 2 & - & 64 & 1.3 & $53-79$ & - & 1711 & 1.1 & $1614-1816$ & 2 & - & 3197 & 1.0 & $3140-3296$ \\
\hline Office & 6 & 1 & 72 & 3.6 & $<\mathrm{LOD}-237$ & - & 668 & 2.4 & $228-1781$ & 6 & 1 & 1510 & 2.1 & $<$ LOD -4144 \\
\hline Canteen & 3 & 3 & - & - & $<\mathrm{LOD}$ & 2 & 44 & 1.5 & $<\mathrm{LOD}-70$ & 3 & 2 & 513 & 1.3 & $<$ LOD-707 \\
\hline Overall & 30 & 10 & 56 & 4.2 & $<$ LOD -579 & 3 & 720 & 5.4 & $<$ LOD-12105 & 30 & 5 & 2276 & 3.5 & $<$ LOD-24211 \\
\hline
\end{tabular}

EDC, electrostatic dust-fall collector; $<$ LOD, below the lower limit of detection; GM, geometric mean; GSD, geometric SD; N, number of measurements; ND, number of non-detectable samples.

on the surfaces of animal exam tables $\left(779 \mathrm{ng} / \mathrm{m}^{2}\right)$ and computer tables $\left(512 \mathrm{ng} / \mathrm{m}^{2}\right)$ was approximately 7 and 4 times, respectively, higher than on equipment tables $\left(118 \mathrm{ng} / \mathrm{m}^{2}\right)(\mathrm{p}<0.05)$. In contrast, the GM level of Fel $d 1$ on the surfaces of computer tables was approximately double that of equipment and animal exam tables. The GM level of endotoxin on the surface of equipment tables was the highest, being threefold higher than on animal exam tables and fourfold higher than on computer tables.

\section{Floor dust sampling}

The overall floor dust levels ranged from 13 to $1228 \mathrm{mg} / \mathrm{m}^{2}$, with the highest exposure level in the waiting room (GM $382 \mathrm{mg} / \mathrm{m}^{2}$ ). The allergen and endotoxin levels of floor dust samples are summarised in table 4 . The highest levels of Fel $d 1$ (GM $39 \mathrm{ng} / \mathrm{m}^{2}$ ) were found in the examination room, and of Can $\mathrm{f} 1\left(\mathrm{GM} 2101 \mathrm{ng} / \mathrm{m}^{2}\right)$ and endotoxin $\left(\mathrm{GM} 7631 \mathrm{EU} / \mathrm{m}^{2}\right)$ in the waiting room. Floor dust allergen and endotoxin content can also be expressed as levels per milligram of dust (ng/mg or EU/ $\mathrm{mg})$. Fel d 1 levels then ranged from $<0.01$ to $5.43 \mathrm{ng} / \mathrm{mg}$ (GM 0.2), Can f 1 levels from 0.01 to $82.92 \mathrm{ng} / \mathrm{mg}$ (GM 4.7) and endotoxin levels from below the LOD to $1080 \mathrm{EU} / \mathrm{mg}$ (GM 22). High correlations were found between levels expressed per square metre and per $\mathrm{mg}$ of dust (Fel d 1: $\mathrm{r}=0.80, \mathrm{p}<0.0001$; Can f 1: $r=0.90, p<0.0001$; endotoxin: $r=0.79, p<0.05$ ).

\section{Comparison between dust sampling methods}

Exposure levels observed in personal samples correlated moderately with those in EDC samples for Fel $\mathrm{d} 1(\mathrm{r}=0.72$; figure $1 \mathrm{~A})$, Can $\mathrm{f} 1(\mathrm{r}=0.62$; figure $1 \mathrm{~B})$ and endotoxin $(\mathrm{r}=0.70$; figure $1 \mathrm{C})$. Exposure levels in EDC samples also correlated moderately with those in floor samples for Fel d 1 ( $r=0.61$; figure $1 \mathrm{G})$ and Can $\mathrm{f} 1$ $(\mathrm{r}=0.64$, figure $1 \mathrm{H})$. In contrast, the levels of Fel $\mathrm{d} 1 \quad(\mathrm{r}=0.34$; figure 1D), Can f $1(r=0.54$; figure $1 \mathrm{E})$ and endotoxin $(r=0.28$; figure $1 \mathrm{~F}$ ) measured in personal samples showed poor correlation with floor dust samples.

Levels of allergens and endotoxin obtained with the EDC samplers exposed for different periods of time were similar (GM ratios ranging from 0.76 to $1.0 ; \mathrm{p}>0.05$ ). Moreover, Fel d 1, Can f 1 and endotoxin levels correlated well between the different time periods $(r>0.81, r>0.94$ and $r>0.70$, respectively; $p<0.05)$.

\section{DISCUSSION}

This is the first study to examine possible exposure to bioaerosols in a companion animal hospital. In general, the different dust collection methods applied in this study showed similar patterns of allergen and endotoxin exposure levels. As expected, allergens and endotoxin levels in airborne samples including personal and EDC samples, were low and allergen levels could only be detected by the sensitive Luminex assay. In contrast, floor dust samples showed much higher allergen and endotoxin levels, which allergens could be detected with an ELISA.

We were able to measure personal levels of Fel $d 1$ and Can $\mathrm{f} 1$ despite the low dust levels. Personal allergen exposure levels of Fel $d 1$ based on job titles were found to be low, often being lower than the LOD with occasional slightly higher levels, suggesting that subjects had only limited exposure to cat allergens. Can $\mathrm{f} 1$ was detected much more often, indicating higher levels of dog allergen than cat allergen. This is likely due to the limited number of cats that are treated in the hospital. During the sampling period, only $15 \%$ of the 290 cats and dogs typically treated every week were cats, thus favouring the abundance of dog allergens.

Only a few studies have reported personal exposure levels of Fel d 1 or Can $\mathrm{f} 1$ in homes, offices and schools, ${ }^{24} 25$ and showed low allergen levels as well. However, a comparison should be made carefully, since sampling and analysis were different. The higher levels of Fel $\mathrm{d} 1$ and Can $\mathrm{f} 1$ for student assistants in the

Table 3 Allergen and endotoxin exposure levels in table surface dust samples by table type

\begin{tabular}{|c|c|c|c|c|c|c|c|c|c|c|c|c|c|}
\hline \multirow[b]{2}{*}{ Table type } & \multirow[b]{2}{*}{$\mathbf{N}$} & \multicolumn{4}{|c|}{ Fel d $1\left(\mathrm{ng} / \mathrm{m}^{2}\right)$} & \multicolumn{4}{|c|}{ Can f $1\left(\mathrm{ng} / \mathrm{m}^{2}\right)$} & \multicolumn{4}{|c|}{ Endotoxin $\left(\mathrm{EU} / \mathrm{m}^{2}\right)$} \\
\hline & & $\overline{\text { ND }}$ & GM & GSD & Range & ND & GM & GSD & Range & ND & GM & GSD & Range \\
\hline Equipment table & 7 & 1 & 11 & 4.7 & $<\mathrm{LOD}-75$ & - & 118 & 5.5 & $5-765$ & - & 12088 & 4.5 & $706-59767$ \\
\hline Animal exam table & 6 & 1 & 13 & 5.7 & $<\mathrm{LOD}-79$ & - & 779 & 3.5 & $120-3849$ & - & 4023 & 5.0 & $565-30841$ \\
\hline Computer table & 12 & - & 22 & 2.7 & $4.4-114$ & - & 512 & 2.0 & $156-1224$ & - & 3294 & 13 & $98-53873$ \\
\hline Lunch table & 2 & 2 & 0.6 & 0 & $<\mathrm{LOD}-06$ & - & 81 & 3.4 & $34-194$ & - & 8266 & 4.0 & $3078-22369$ \\
\hline Overall & 27 & 4 & 13 & 4.7 & $<\mathrm{LOD}-114$ & - & 336 & 4.0 & $5-3849$ & - & 5324 & 8.1 & $98-59767$ \\
\hline
\end{tabular}

$<\mathrm{LOD}$, below the lower limit of detection; GM, geometric mean; GSD, geometric SD; N, number of measurements; ND, number of non-detectable samples. 


\section{Original article}

Table 4 Allergen and endotoxin exposure levels in floor dust samples at different locations

\begin{tabular}{|c|c|c|c|c|c|c|c|c|c|c|c|c|c|}
\hline \multirow[b]{2}{*}{ Location } & \multirow[b]{2}{*}{$\mathbf{N}$} & \multicolumn{4}{|c|}{ Fel d $1\left(\mathrm{ng} / \mathrm{m}^{2}\right)$} & \multicolumn{4}{|c|}{ Can f $1\left(\mathrm{ng} / \mathrm{m}^{2}\right)$} & \multicolumn{4}{|c|}{ Endotoxin $\left(\mathrm{EU} / \mathrm{m}^{2}\right)$} \\
\hline & & ND & GM & GSD & Range & ND & GM & GSD & Range & ND & GM & GSD & Range \\
\hline Operation room & 16 & - & 4 & 3.2 & $1.0-139$ & - & 46 & 2.7 & $7-259$ & 1 & 403 & 3.1 & $<$ LOD-6996 \\
\hline Recovery room & 6 & - & 15 & 2.6 & $4.4-40$ & - & 366 & 2.2 & $128-880$ & - & 750 & 2.9 & $125-2994$ \\
\hline Intensive care unit & 8 & - & 8 & 6.2 & $0.2-56$ & - & 441 & 3.3 & $29-1432$ & - & 1790 & 2.2 & $362-4811$ \\
\hline Inpatient ward & 7 & - & 16 & 3.1 & $6.0-145$ & - & 324 & 3.4 & $43-2462$ & - & 4273 & 1.9 & $2005-10448$ \\
\hline Examination room & 17 & - & 39 & 3.4 & $3.2-183$ & - & 1148 & 2.0 & $218-8119$ & - & 2515 & 3.8 & $334-21823$ \\
\hline Practical teaching room & 7 & - & 24 & 4.1 & $1.8-91$ & - & 1206 & 2.4 & $489-6111$ & - & 4537 & 3.6 & $1978-72506$ \\
\hline Ultrasound room & 7 & - & 34 & 2.9 & $6.1-124$ & - & 798 & 2.5 & $227-4546$ & - & 1772 & 1.5 & $1077-3393$ \\
\hline Office & 21 & - & 7 & 2.1 & $1.5-28$ & - & 222 & 3.6 & $15-1512$ & - & 1863 & 3.0 & $254-27655$ \\
\hline Canteen & 14 & - & 2 & 2.6 & $0.3-9$ & 3 & 11 & 5.0 & $<\mathrm{LOD}-110$ & - & 1188 & 5.4 & $135-100776$ \\
\hline Overall & 110 & - & 11 & 4.3 & $0.2-183$ & 3 & 240 & 7.1 & $<\mathrm{LOD}-13644$ & 1 & 1702 & 4.0 & $<\mathrm{LOD}-100776$ \\
\hline
\end{tabular}

$<\mathrm{LOD}$, below the lower limit of detection; GM, geometric mean; GSD, geometric SD; N, number of measurements; ND, number of non-detectable samples.

intensive care unit might reflect the greater proportion of cats and dogs in this area of the hospital, and the nature of the tasks performed. This is in contrast to the low personal allergen exposures in the operation room, likely due to more regular and intensive cleaning and less contact with active animals. None- theless, personal allergen exposure levels in this setting occasionally were high and at a level thought to induce asthma symptoms, particularly in those susceptible to cat and dog allergens. $^{26}$ The low endotoxin levels in the current study are in agreement with earlier findings for veterinarians working with
A Personal versus EDC samples $(R=0.72, p<0.002, n=15)$

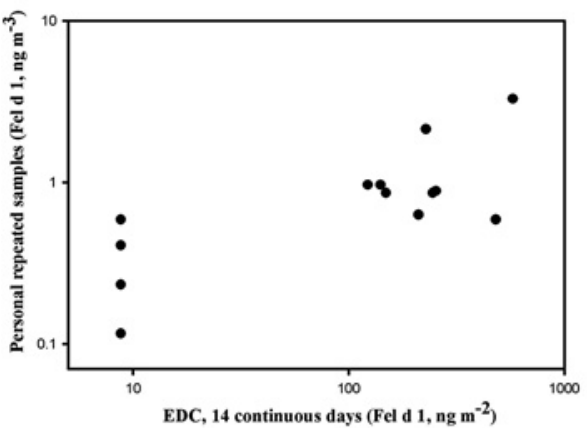

D Personal versus floor samples $(R=0.34, p<0.01, n=57)$

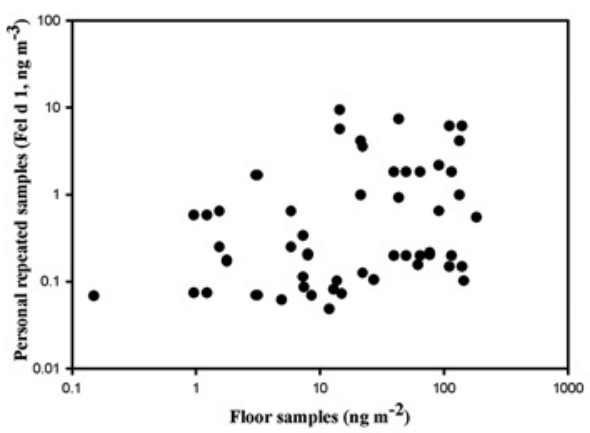

G Floor versus EDC samples $(R=0.61, p<0.0002, n=30)$

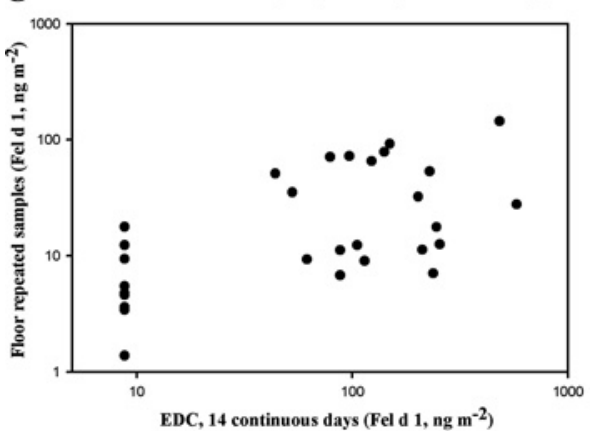

B Personal versus EDC samples $(R=0.62, p<0.01, n=15)$

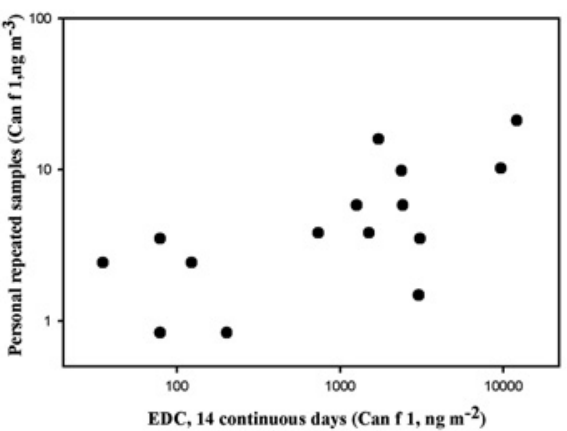

E Personal versus floor samples $(R=0.54, p<0.01, n=57)$

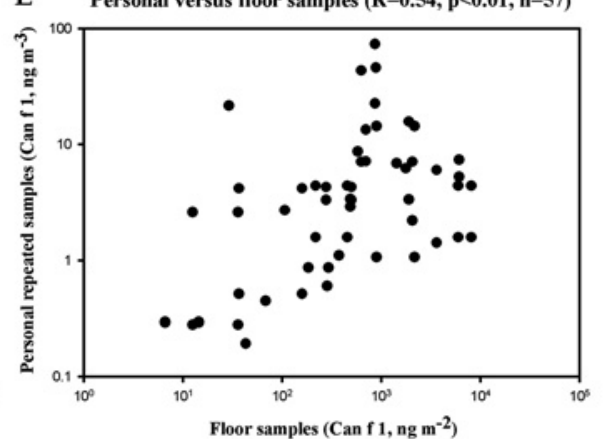

H Floor versus EDC samples $(R=0.64, p<0.0001, n=30)$

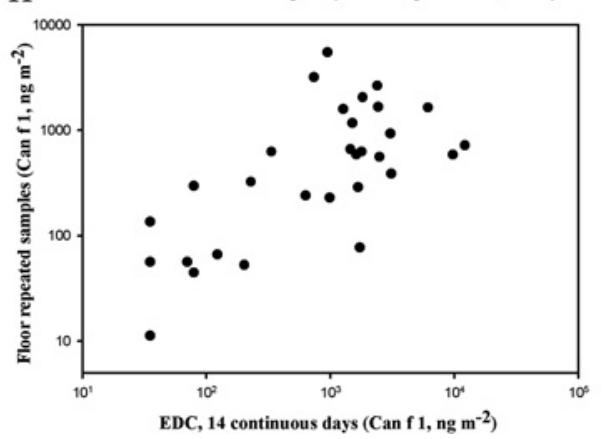

C Personal versus EDC samples $(R=0.70, p=0.003, n=15)$

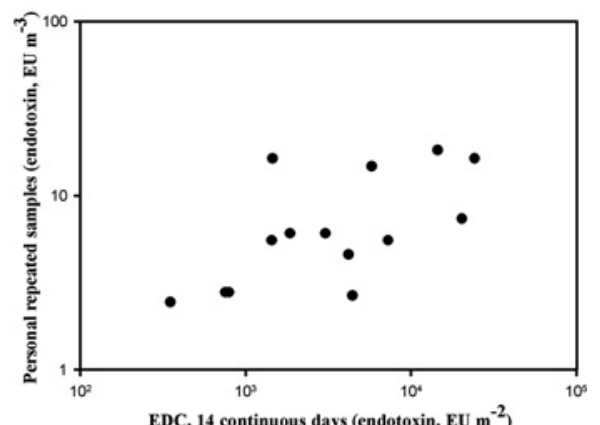

F Personal versus floor samples $(R=0.28, p=0.03, n=57)$

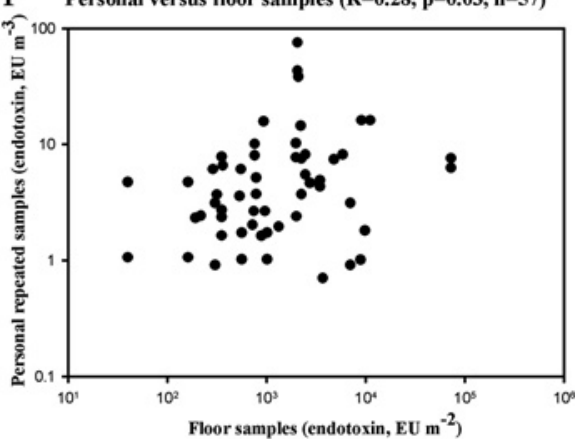

I Floor versus EDC $(R=0.35, p=0.05, n=30)$

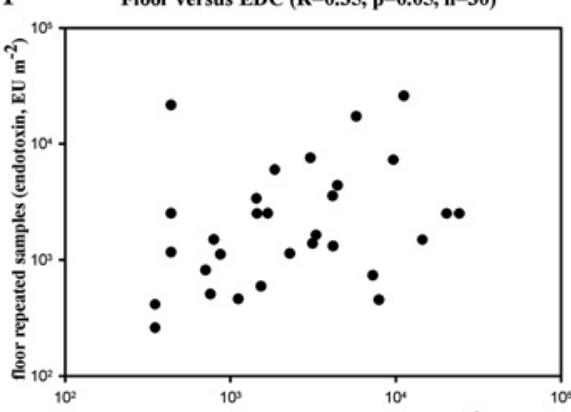

EDC, 14 continuous days (endotoxin $\mathrm{EU}^{-2}$ )

Figure 1 Correlations between various sampling methods for Fel $d 1(A, D, G)$, Can $f 1(B, E, H)$ and endotoxin levels $(C, F, I)$. A, B and $C$, personal versus EDC sampling; D, E and F, personal versus floor dust sampling; $G, H$ and $I$, floor dust versus EDC sampling. 
companion animals, ${ }^{12}$ in comparison to higher levels for veterinarians working in animal husbandry, poultry or mixed practices. ${ }^{12}$ Nonetheless, as also for endotoxin, job titles or areas with closer contact with animals showed the highest exposure levels.

The Fel $\mathrm{d} 1$ levels of floor dust samples in the current study were markedly higher than those previously found in office work places, ${ }^{27}$ while levels were lower than those reported from floor surfaces in homes with cats. ${ }^{14} 28$ A possible explanation for the lower levels of Fel $\mathrm{d} 1$ is the type of floor covering, since most of our sampling was performed on smooth floors, while sampling in homes was frequently conducted on carpeted floors, known to result in higher levels. ${ }^{29}$ Unlike for Fel d 1, less data are available for Can $\mathrm{f} 1$. The Can $\mathrm{f} 1$ levels of floor dust samples were comparable to those from public spaces ${ }^{24}$ and homes with dogs. ${ }^{30}$

This study showed that table surfaces can act as a potential secondary source for exposure. This has rarely been explored in occupational settings. There are a few studies reporting allergens on table surfaces from schools, ${ }^{26} 31$ but sampling methods are different and levels of allergens are presented in different units. This makes it difficult to compare results; however, those studies also identified table surfaces as a potential secondary source for Fel d 1 and Can $\mathrm{f} 1$ exposure.

We showed that it is feasible to detect allergens and endotoxin in settling dust samples collected with the EDC in an occupational environment, whereas active stationary samples were below the LOD. The better performance of the EDC in determining ambient airborne exposure levels can likely be attributed to the longer average time of sampling. The levels observed at samplers exposed to the air for 14 continuous days, 10 days including night time, and 10 work days were similar, which suggests that the contribution of weekends or nights to the exposure might be negligible. Therefore, measurement of allergens or endotoxin based on 14 continuous days (sampling time) might be preferred for practical reasons.

Moderate to good correlations were found between allergen or endotoxin levels in EDC samples and personal samples or floor dust samples, whereas only weak agreements between personal samples and floor dust samples were found. This is similar to previous results for endotoxin, ${ }^{18}$ and for allergens considering the association between floor dust and active airborne dust. ${ }^{32} 33$ It seems that the dust collected with the EDC in occupational environmental settings might reflect personal exposure, and is a good alternative for ambient stationary sampling in cases where personal sampling cannot be performed.

We found that the canteen may also be a secondary source for Fel $\mathrm{d} 1$ and Can $\mathrm{f} 1$ exposure. It has previously been shown that Fel $\mathrm{d} 1$ and Can $\mathrm{f} 1$ can transfer to other environments due to transportation via clothes ${ }^{34}$ and hair. ${ }^{35}$ In this case, transfer to the canteen is likely due to transfer on clothing and the fact that pet owners are allowed to bring their pets into a separated area of the canteen. Avoiding this seems to be the best intervention measure to reduce allergen levels. A four- to sixfold reduction in Fel d 1 levels has been reported after clean clothes were worn. ${ }^{34}$

Floor and table surface dust sample results have important implications for investigating the effect of cleaning. Lower floor allergen levels were observed in the inpatient ward, because the floor surface in that area of the hospital was cleaned twice daily with water. In contrast, observed higher allergen levels in the intensive care unit and examination room might be due to oncedaily water cleaning and dry cleaning in these locations, respectively. Also differences between levels of dust from computer, equipment and animal exams tables could likely be explained by cleaning patterns.
Up to now, threshold limit values for Fel $\mathrm{d} 1$ and Can $\mathrm{f} 1$ have not been established. ${ }^{36}$ Nonetheless, it has been suggested that $1 \mu \mathrm{g} / \mathrm{g}$ of Fel $\mathrm{d} 1$ was associated with sensitisation, and $8 \mu \mathrm{g} / \mathrm{g}$ was related to asthma. ${ }^{30}{ }^{37}$ Similarly, levels of Can $\mathrm{f} 1$ to induce sensitisation and asthma symptoms were 2 and $10 \mu \mathrm{g} / \mathrm{g}$, respectively. ${ }^{30}$ In the present study only floor dust samples can be expressed in such measures. The Fel d 1 levels of all floor samples were below $8 \mu \mathrm{g} / \mathrm{g}$, and 10 out of 110 samples were higher than $1 \mu \mathrm{g} / \mathrm{g}$. For Can f 1, 82 out of 110 samples were higher than $2 \mu \mathrm{g} / \mathrm{g}$, and 41 out of 110 samples were higher than $10 \mu \mathrm{g} / \mathrm{g}$, indicating probable health risks for the working population.

\section{CONCLUSIONS}

Our data demonstrated that allergen exposure occurs during veterinary practice, while personal endotoxin levels were low. By using a sensitive allergen assay, quantifying allergen levels in airborne, personal and settling dust samples was possible despite the low dust levels. The EDC sampler can be used as a complementary method. The surfaces of floors and tables were found to be potent secondary sources for bio-aerosol exposure. However, further studies should be conducted to evaluate whether observed exposure levels affect the health of employees and students.

Acknowledgements The authors would like to thank staff and students for their participation. Roderik Overmars, Jack Spithoven and Nena Burger are acknowledged for the laboratory analyses, and Virissa Lenters and Linda McPhee for revising the manuscript.

\section{Competing interests None.}

Provenance and peer review Not commissioned; externally peer reviewed.

\section{REFERENCES}

1. Gehring U, Heinrich J, Jacob B, et al. Respiratory symptoms in relation to indoor exposure to mite and cat allergens and endotoxins. Indoor Factors and Genetics in Asthma (INGA) Study Group. Eur Respir J 2001;18:555-63.

2. Takkouche B, Gonzalez-Barcala FJ, Etminan M, et al. Exposure to furry pets and the risk of asthma and allergic rhinitis: a meta-analysis. Allergy 2008;63:857-64.

3. Susitaival P, Kirk JH, Schenker MB. Atopic symptoms among California veterinarians. Am J Ind Med 2003:44:166-71.

4. Bush RK, Wood RA, Eggleston PA. Laboratory animal allergy. J Allergy Clin Immunol 1998;102:99-112.

5. Wood RA. Laboratory animal allergens. ILAR J 2001;42:12-16.

6. Aoyama K, Ueda A, Manda F, et al. Allergy to laboratory animals: an epidemiological study. Br J Ind Med 1992:49:41-7.

7. Gehring U, Strikwold M, Schram-Bijkerk D, et al. Asthma and allergic symptoms in relation to house dust endotoxin: Phase Two of the International Study on Asthma and Allergies in Childhood (ISAAC II). Clin Exp Allergy 2008;38:1911-20.

8. Thorne PS, Kulhankova K, Yin M, et al. Endotoxin exposure is a risk factor for asthma: the national survey of endotoxin in United States housing. Am J Respir Crit Care Med 2005;172:1371-7.

9. Liebers V, Raulf-Heimsoth $M$, Bruning T. Health effects due to endotoxin inhalation (review). Arch Toxicol 2008;82:203-10.

10. Spaan S, Wouters IM, Oosting I, et al. Exposure to inhalable dust and endotoxins in agricultural industries. J Environ Monit 2006;8:63-72.

11. Pacheco KA, McCammon C, Thorne PS, et al. Characterization of endotoxin and mouse allergen exposures in mouse facilities and research laboratories. Ann Occup Hyg 2006;50:563-72.

12. Elbers AR, de Vries M, van Gulick PJ, et al. Veterinary practice and occupational health. An epidemiological study of several professional groups of Dutch veterinarians. II. Peak expiratory flow variability, dust and endotoxin measurements, use of respiratory protection devices, and time distribution of professional activities. Vet 0 1996;18:132-6.

13. Karlsson AS, Hedren M, Almqvist C, et al. Evaluation of Petri dish sampling for assessment of cat allergen in airborne dust. Allergy 2002;57:164-8.

14. Parvaneh S, Elfman $L$, Ahlf $E$, et al. A new method for collecting airborne allergens Allergy 2000;55:1148-54.

15. Renstrom A. Exposure to airborne allergens: a review of sampling methods. J Environ Monit 2002;4:619-22.

16. Hamilton RG. Assessment of indoor allergen exposure. Curr Allergy Asthma Rep 2005;5:394-401.

17. Bogdanovic J, Koets $\mathrm{M}$, Sander I, et al. Rapid detection of fungal alpha-amylase in the work environment with a lateral flow immunoassay. J Allergy Clin Immunol 2006;118:1157-63 
18. Noss I, Wouters IM, Visser M, et al. Evaluation of a low-cost electrostatic dust fall collector for indoor air endotoxin exposure assessment. Appl Environ Microbiol 2008;74:5621-7.

19. Schram-Bijkerk D, Doekes G, Douwes J, et al. Bacterial and fungal agents in house dust and wheeze in children: the PARSIFAL study. Clin Exp Allergy 2005;35:1272-8.

20. Schram D, Doekes G, Boeve M, et al. Bacterial and fungal components in house dust of farm children, Rudolf Steiner school children and reference children-the PARSIFAL. Study Allergy 2005;60:611-18.

21. van Strien RT, Koopman LP, Kerkhof M, et al. Mite and pet allergen levels in homes of children born to allergic and nonallergic parents: the PIAMA study. Environ Health Perspect 2002;110:A693-8.

22. Earle CD, King EM, Tsay A, et al. High-throughput fluorescent multiplex array for indoor allergen exposure assessment. J Allergy Clin Immunol 2007;119:428-33.

23. Spaan S, Doekes G, Heederik D, et al. Effect of extraction and assay media on analysis of airborne endotoxin. Appl Environ Microbiol 2008;74:3804-11.

24. Custovic A, Green R, Taggart SC, et al. Domestic allergens in public places. II: Dog (Can f1) and cockroach (Bla g 2) allergens in dust and mite, cat, dog and cockroach allergens in the air in public buildings. Clin Exp Allergy 1996;26:1246-52.

25. Almqvist C, Larsson PH, Egmar AC, et al. School as a risk environment for children allergic to cats and a site for transfer of cat allergen to homes. J Allergy Clin Immunol 1999;103:1012-17.

26. Munir AK, Einarsson R, Schou C, et al. Allergens in school dust. I. The amount of the major cat (Fel d I) and dog (Can f I) allergens in dust from Swedish schools is high enough to probably cause perennial symptoms in most children with asthma who are sensitized to cat and dog. J Allergy Clin Immunol 1993;91:1067-74.

27. Perfetti L, Ferrari M, Galdi E, et al. House dust mites (Der p 1, Der $\mathrm{f} 1$ ), cat (Fel d 1) and cockroach (Bla g 2) allergens in indoor work-places (offices and archives). Sci Total Environ 2004:328:15-21.
28. Custovic A, Simpson A, Pahdi $\mathrm{H}$, et al. Distribution, aerodynamic characteristics, and removal of the major cat allergen Fel $\mathrm{d} 1$ in British homes. Thorax 1998; 53:33-8

29. Van Strien RT, Verhoeff AP, Brunekreef B, et al. Mite antigen in house dust: relationship with different housing characteristics in The Netherlands. Clin Exp Allergy 1994:24:843-53

30. Ingram JM, Sporik R, Rose G, et al. Quantitative assessment of exposure to dog (Can $f 1$ ) and cat (Fel d 1) allergens: relation to sensitization and asthma among children living in Los Alamos, New Mexico. J Allergy Clin Immunol 1995:96:449-56.

31. Munir AK, Einarsson R, Dreborg SK. Mite (Der $\mathrm{pl}$ I, Der $\mathrm{fl}$ ), cat (Fel $\mathrm{d}$ I) and dog (Can $\mathrm{f}$ I) allergens in dust from Swedish day-care centres. Clin Exp Allergy 1995:25:119-26.

32. O'Meara T, Tovey E. Monitoring personal allergen exposure. Clin Rev Allergy Immunol 2000;18:341-95

33. Bollinger ME, Eggleston PA, Flanagan E, et al. Cat antigen in homes with and without cats may induce allergic symptoms. J Allergy Clin Immunol 1996:97:907-14

34. De Lucca SD, O'Meara TJ, Tovey ER. Exposure to mite and cat allergens on a range of clothing items at home and the transfer of cat allergen in the workplace. $J$ Allergy Clin Immunol 2000;106:874-9.

35. Karlsson AS, Renstrom A. Human hair is a potential source of cat allergen contamination of ambient air. Allergy 2005:60:961-4

36. Andersen BM, Solheim N, Kruger 0, et al. [Floor cleaning methods of patients room. Effect on bacteria, dirt and particles]. Tidsskr Nor Laegeforen 1997;117:838-41.

37. Rijnkels JM, Smid T, Van den Aker EC, et al. Prevention of work-related airway allergies; summary of the advice from the Health Council of the Netherlands. Allergy 2008:63:1593-6. 